\title{
THE IMPORTANCE OF SUBCUTANEOUS TISSUE THICKNESS FOR THE OCCURRENCE OF SURGICAL SITE INFECTION AFTER LUMBAR DISC SURGERY
}

\author{
๑ Illker GÜLEÇ1', ๑ Feyza KARAGÖZ GÜZEY1 \\ University of Health Sciences Turkey, Bağcılar Training and Research Hospital, Clinic of Neurosurgery, Istanbul, Turkey
}

\begin{abstract}
Objective: Previous studies have shown that the length of the surgical path is important in surgical wound infection after a major lumbar surgery. We investigated for the first time the relationship between wound infection occurrence after lumbar disc surgery and subcutaneous tissue thickness.

Materials and Methods: We retrospectively identified 1,275 patients who underwent lumbar disc surgery between 2015 and 2020.0 . these, 32 patients were hospitalised with a diagnosis of surgical superficial or deep wound infection. Demographic data, comorbidities, body mass index and body surface areas (BSAs) of the patients were recorded. Subcutaneous adipose tissue thickness and distance from the lamina to the skin were measured on magnetic resonance imaging examinations. Results were compared with that of the control group.

Results: Superficial and deep wound infections were detected in $62.5 \%$ and $37.5 \%$ of patients, respectively. Age $(p=0.182)$, comorbidities $(p=0.425)$, body mass index $(p=0.182), B S A(p=0.569)$ and subcutaneous adipose tissue $(p=0.110)$ did not contribute to the occurrence of wound infection after lumbar disc surgery. However, the distance between the lamina and skin $(p=0.017)$ was found to be statistically different in women with a wound infection.

Conclusion: We found that that a long distance between the lamina and skin in women might be a risk factor for the occurrence of surgical wound infections.

Keywords: Discectomy, infection, wound, subcutaneous, surgical
\end{abstract}

\section{INTRODUCTION}

Surgical site infection (SSI) after discectomy is rare, but debilitating and potentially life-threatening ranging from $0.09 \%$ to $2.1 \%^{(1-5)}$. It also significantly reduces patient satisfaction due to re-hospitalisation ${ }^{(6)}$ and increased length of hospital stay ${ }^{(7)}$. Despite intensive studies to identify its predisposing risk factors, it has not yet been fully elucidated ${ }^{(8,9)}$. Advanced age; smoking; comorbidities such as diabetes, hypertension, etc.; steroids use and surgical-related causes have been listed as risk factors ${ }^{(1,2,10-13)}$.

The body mass index (BMI) has for long been used in spinal surgery as a parameter to predict the occurrence of SS| $\left.\right|^{5,11-}$ 13). Growing evidence from studies indicates that a high BMI contributes to reoperation ${ }^{(14)}$, and SSI occurrence( ${ }^{(8)}$. However, it was suggested that the definition of obesity using the BMI did not accurately reflect the regional adipose tissue because it did not take into account the presence of muscle tissue ${ }^{(15)}$. To solve this problem, some claimed that the thickness of the subcutaneous tissues in the surgical pathway, rather than the fat distribution of the whole body, could be an important causal factor ${ }^{(16-19)}$ Mehta et al. ${ }^{(16)}$ evaluated the subcutaneous fat tissue (SFT) thickness and distance from the lamina to the skin (DLS) in patients with spinal who developed SSI. They suggested that SFT thickness and DLS provided stronger data to predict the likelihood of SSI occurrence, which was confirmed by others with similar data ${ }^{(17,19)}$.

Therefore, we investigated the effects of BMI, body surface area (BSA), SFT and DLS on postoperative SSI occurrence in patients with lumbar disc surgery.

\section{MATERIALS AND METHODS}

Patients who underwent microdiscectomy with a diagnosis of lumbar disc herniation (LDH) between 2015 and 2020 and

Address for Correspondence: Illker Güleç, University of Health Sciences Turkey, Bağclar Training and Research Hospital, Clinic of Neurosurgery, istanbul, Turkey E-mail: ilkergulec@gmail.com Received: 19.10.2020 Accepted: 02.11.2020 ORCID:

ORCID ID: orcid.org/0000-0003-4207-238X 
subsequently developed SSI were retrospectively analysed. We found that 32 patients developed SSI, which was classified as either superficial or deep. BMI, BSA, SFT and DLS were measured in all the patients. The measured values were used to determine associations with SSI occurrence. This study was approved by the local ethics committee (registration number: 05/15/2020-2020.05.1.05.037).

Patients who underwent surgery at one or two levels by the microdiscectomy procedure were included in the study. Patients with a spinal fracture, infection and tumour, spondylolisthesis, deformity and previous spinal surgery were not included in the study.

Incisional SSI is classified as superficial (from the skin to the lumbodorsal fascia) or deep (lumbodorsal fascia and below). We classified our patients as those with superficial or deep wound infection. The representative cases for superficial and deep infections are presented in Figures 1 and 2, respectively.

The results were compared with those of 80 women and 80 men, selected randomly from a pool of patients who were operated in the same date range and with the same surgical approach, but did not develop SSI. All the patients received a single dose of antibiotic prophylaxis intravenously 30 minutes before the surgery. In all surgeries, the same protocol was used for the preparation of the surgical area.

In the follow-up, patients with wound problems that required antimicrobial treatment were re-hospitalised. Each patient was questioned and investigated for localised pain, erythema, oedema, incision dehiscence, purulent drainage from the incision and fever $>38^{\circ} \mathrm{C}$. The last magnetic resonance imaging (MRI) examination of the patients shortly before the lumbar disc surgery was obtained, and a new MRI was performed when hospitalised for the SSI. Tissue samples submitted for culture that were obtained by wound swap, needle aspiration or the open surgery method were recorded.

The BMI classification was used with its definitions follows: BMI: $18.5-24.9 \mathrm{~kg} / \mathrm{m}^{2}$ (normal), $25.0-29.9 \mathrm{~kg} / \mathrm{m}^{2}$ (pre-Obesity), $30.0-34.9 \mathrm{~kg} / \mathrm{m}^{2}$ (Obesity class I), $35.0-39.9 \mathrm{~kg} / \mathrm{m}^{2}$ (Obesity class II) and above $40 \mathrm{~kg} / \mathrm{m}^{2}$ (Obesity class III) in adults. BSA was calculated and expressed in $\mathrm{m}^{2(20)}$.

The data from lumbar MRI scans belonging to the patients and saved in Digital Imaging and Communications in Medicine (DICOM) format were obtained with a software provided by DICOM company. SFT and DLS for each patient were measured on the axial and/or sagittal T1-weighted image (presented in Figure 3). The measurement was made by two independent observers, and the average of the results was considered.

\section{Statistical Analysis}

Nominal data are presented as percentages while numerical data are presented as average and standard deviation. Comparison between groups was done using the chi-square and Fisher's exact test depending on the number of group subjects for nominal data, Kruskal-Wallis and Mann-Whitney U tests for

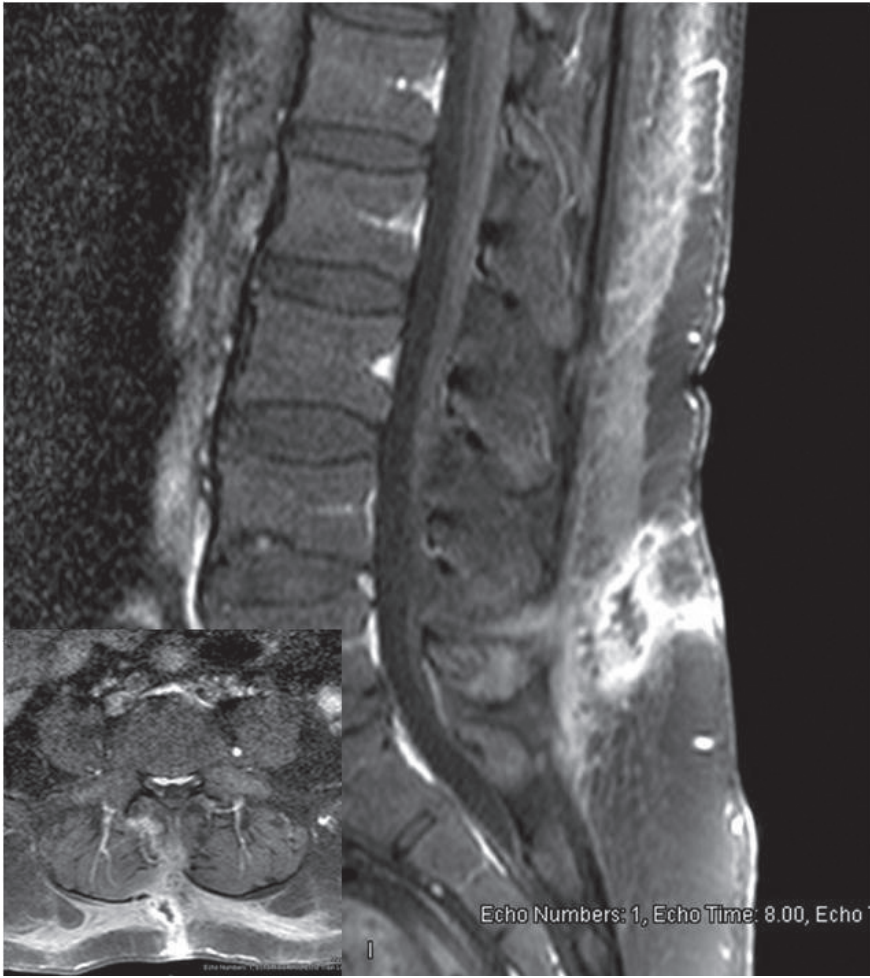

Figure 1. The figure shows a superficial SSI in the T1-weighted contrast MRI of a patient who underwent L5-S1 discectomy

SSI: Surgical site infection, MRI: Magnetic resonance imaging

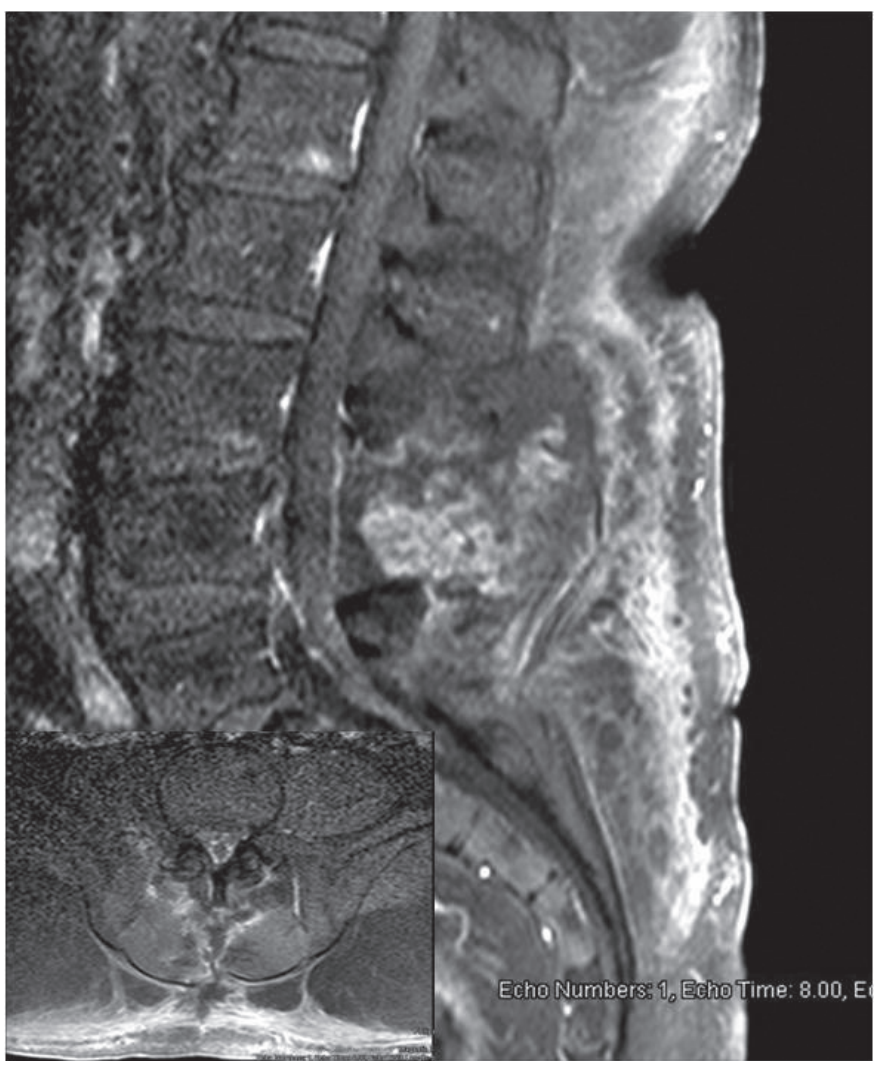

Figure 2. The figure shows a deep SSI in the T1-weighted contrast MRI of a patient who underwent L4-5 discectomy

SSI: Surgical site infection, MRI: Magnetic resonance imaging 
sequential data and variance analysis and t-test for numerical data. Bonferroni correction was used when variance analysis was done. $P<0.05$ was considered significant. Professional help was obtained for the statistical calculations.

\section{RESULTS}

SSI was detected in 32 patients (2.5\%) after the LDH surgery. Characteristics of the study population and comorbidities are presented in Table 1.

The most common complaint at re-admission was low back pain and temperature increase in the incision line and the most common finding was severe low back pain with percussion and wound dehiscence. In the 32 patients who developed SSI, 36 levels of lumbar disc surgery were performed (four surgeries were performed at two levels). The most frequent level was L4-5 (22 cases, $61.2 \%)$, followed by L4-5 (10 cases, 27.8\%), L2 - 3 (2 cases, 5.5\%) and L2-3 level (2 cases, 5.5\%). The superficial SSI was encountered in $71.9 \%$ of patients (11 women vs 12 men) and deep in $28.1 \%$ (4 women vs 5 men).

We evaluated whether the BMI,BSA, SFT and DLS had any effect on SSI occurrence (presented in Table 2). In the SSI group, 33.3\% of the women were pre-obese, $67.7 \%$ were obese, and this rate was $64.8 \%$ and $35.2 \%$ for men, respectively. Comparing the group of men with and without SSI, there was no statistically significant difference in terms of age, comorbidity, SFT, DLS, $\mathrm{BMI}$ and BSA (no data provided). When comparing the group of women with and without SSI, there was no statistically significant difference in terms of age, comorbidity, SFT, BMI and BSA (no data provided). When the SSI and non-SSI groups were compared, the DLS value was found to be statistically different in the SSI group $(p=0.017)$ (presented in Table 2). The factor that made the statistical significance was women. Compared to the non-infected group of women with SSI, the DLS value was to be found statistically different in women $(p=0.014)$. Therefore, it is thought that DLS may be a risk factor for SSI occurrence in women.

The bacteria isolation rate was $65.6 \%(n=21 / 32)$. Culture sampling was performed in five patients during debridement. No intervention was conducted because five patients were considered to have no material to be sampled. Gram-positive cocci were responsible for $61.9 \%$ of the SSIs, while Gramnegative cocci were responsible for $38.1 \%$. No organism was isolated in five patients (15.6\%), three of whom had deep and two had superficial infections. Twenty-one patients were treated with an antibiotic regimen determined by the antibiogram results. The remaining 11 patients were treated with antianaerobic and antiaerobic antibiotics.

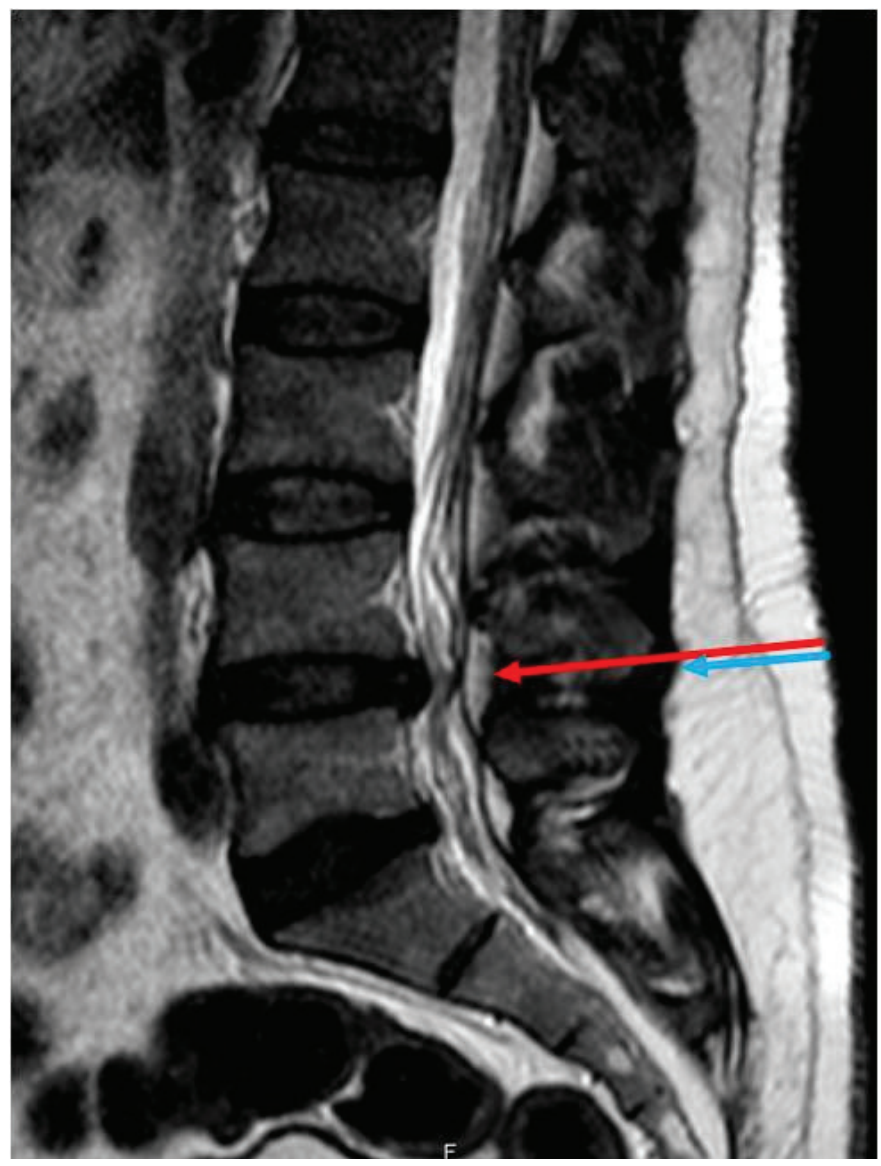

Figure 3. The figure shows the measurement of subcutaneous fat tissue (blue arrow) and distance of the lamina-to-skin (red arrow) on the T1-weighted MRI along the surgical route MRI: Magnetic resonance imaging

Table 1. The table shows the age, sex and comorbidities of the patients included in the study

\begin{tabular}{|c|c|c|c|}
\hline & $\begin{array}{l}\text { Patients in the control } \\
\text { group }(n=160)\end{array}$ & $\begin{array}{l}\text { Patients in the SSI } \\
\text { group }(n=32)\end{array}$ & $\mathbf{p}$ \\
\hline Age, mean ( \pm SD), year & $50.5( \pm 12.4)$ & $48.3( \pm 11.9)$ & 0.747 \\
\hline Hypertension & 45 & 9 & 0.577 \\
\hline IHD & 9 & 4 & 0.237 \\
\hline Comorbidities (total) & 102 & 25 & - \\
\hline
\end{tabular}

SSI: Surgical site infection, SD: Standard deviation, IHD: Ischemic heart disease, COPD: Chronic obstructive pulmonary disease, RA: Rheumatoid arthritis, $\mathrm{n}$ : Number 
Table 2. The table shows the statistical comparisons of BMI, BSA, and radiological measurements of patients with and without SSI

\begin{tabular}{|c|c|c|c|}
\hline & $\begin{array}{l}\text { Patients in the control group } \\
(n=160)\end{array}$ & $\begin{array}{l}\text { Patients in the SSI group } \\
(n=32)\end{array}$ & p \\
\hline BMI, mean ( \pm SD), $\mathrm{kg} / \mathrm{m}^{2}$ & $28.8( \pm 4.83)$ & $30.1( \pm 4.96)$ & 0.182 \\
\hline SFT, mean ( \pm SD), mm & $27.4( \pm 11.9)$ & $31.05( \pm 11.36)$ & 0.110 \\
\hline DLS, mean ( \pm SD), mm & $61.73( \pm 13.0)$ & $67.92( \pm 14.35)$ & $0.017^{*}$ \\
\hline
\end{tabular}

SSI: Surgical site infection, SD: Standard deviation, BMI: Body mass index, BSA: Body surface area, SFT: Thickness of subcutaneous fat tissue, DLS: Distances from the lamina to the skin, ${ }^{*}$ Statistically significant $(p<0.05)$, n: Number

The antimicrobial treatment duration of the patients ranged from seven to 37 days. In addition, one of the patients received hyperbaric oxygen therapy as an additional treatment. The average hospital stay for the patients with SSI (range: 4 to 26 days) was $11.5 \pm 5.9$ days $(10.2 \pm 4.7$ for women and $12.5 \pm 6.7$ for men).

\section{DISCUSSION}

Depending on the technique of the intervention, wound complications occurred at a rate of $2.1 \%$ in microdiscectomy, $1.2 \%$ in microendoscopic discectomy and $0.5 \%$ in the percutaneous discectomy procedure ${ }^{(5)}$. Golinvaux et al. ${ }^{(4)}$ compared patients who underwent a discectomy in the Spine Patient Outcomes Research Trial (SPORT) study ( $\mathrm{n}=232$ ), a randomised controlled trial, with patients registered in the National Surgical Quality Improvement Program (NSQIP) study $(n=6,842)$. The analysis revealed that the incidence of superficial SSI in the SPORT study was $2 \%$ and deep SSI was $0 \%$, whereas in the NSQIP study, it was $0.6 \%$ and $0.3 \%$, respectively. Smith et al. ${ }^{(21)}$ analysed 7,213 discectomy patients and found that SSI was present in $0.9 \%$ (superficial in $0.5 \%$, deep in $0.4 \%$ ) of the patients. In the study that used a minimally invasive surgical technique, the SSI occurred in $0.09 \%$ of the 4,350 patients (all deep) ${ }^{(3)}$. In a similar study conducted using the same method with 4,027 patients, the rate of SSI was $0.65 \%$ (superficial in $0.42 \%$, deep in $0.23 \%$ ), and it was concluded that MIST is an independent protective factor against infection ${ }^{(2)}$. In a systematic review, Zijlmans et al.(22) investigated whether postoperative deep haematoma ranging from $0.15 \%$ to $2 \%$ was the source of infection, and found no statistical difference in the SSI rate between those who were drained $(0.47 \%)$ and those who were not $(0.88 \%)$. The rate of patients with SSI in our single-centre study was $2.5 \%$, which was considerably higher than that in the literature. On the other hand, superficial SSI was detected in $2 / 3$ of the total population in accordance with previous studies.

Numerous studies focusing on the effect of BMI on SSI occurrence after discectomy have been published ${ }^{(4,7,12,13)}$. In the report comparing the results of the two major studies median BMI was found to be $27.8 \mathrm{~kg} / \mathrm{m}^{2}$ for SPORT and $29.6 \mathrm{~kg} / \mathrm{m}^{2}$ for
NSQIP, median values of both studies were in the pre-obesity class, and the SSI occurrence rate was less than $2 \%\left({ }^{(4)}\right.$. In daily hospitalised patients, BMI and SSI were $29.4 \mathrm{~kg} / \mathrm{m}^{2}$ and $1.13 \%$, respectively ${ }^{(12)}$. Rinn et al. ${ }^{(13)}$ compared the SSI results in patients with BMI greater and less than $30 \mathrm{~kg} / \mathrm{m}^{2}$ and found an SSI rate of $2 \%$ in both groups. Fakouri et al.(7) evaluated two groups of patients, non-obese and obese, with a median BMI of $24 \mathrm{~kg} /$ $\mathrm{m}^{2}$ and $38.7 \mathrm{~kg} / \mathrm{m}^{2}$, respectively. They found that the risk of rehospitalisation in patients double when the $\mathrm{BMI}$ is greater than $40 \mathrm{~kg} / \mathrm{m}^{2}$. The above-mentioned articles concluded that obesity is not a risk factor for SSI. In our study, the BMI was higher in patients with SSI than in those without SSI, but no statistically significant difference $(p=0.182)$ was found. We concluded that $\mathrm{BMI}$ is not a risk factor, which is consistent with the results of previous studies.

A study reported that the BMI result does not accurately reflect the regional adipose tissue ${ }^{(15)}$. It is also unable to distinguish between fat and lean mass, whereas the body composition consists of fat, muscles, bones, water and other tissues. Therefore, researchers attempted to obtain a new parameter to estimate SSI by measuring regional subcutaneous tissue ${ }^{(16-19)}$. Mehta et al. ${ }^{(16)}$ examined the SFT and DLS by taking measurements at the L4 level in 28 cases who underwent fusion surgery. They found higher SFT $(p=0.035)$ and DLS values $(p=0.046)$ in infected patients than in healthy subjects and concluded that SFT is more valuable in predicting SSI than BMI. Li et al.(18) studied the SFT in 20 patients with transforaminal lumbar interbody fusion (measured at the same level) and concluded that it is an independent risk factor for SSI occurrence $(p=0.001)$. Lee et al. ${ }^{(17)}$ evaluated subcutaneous adipose tissue with multi-level measurements from T12 to L5. They found that each mm of SFT increase leads to a $6 \%$ increase in SSI rate, and if the thickness is above $5 \mathrm{~cm}$, it leads to a 4 -fold increase, which supports the finding that SFT has a statistically stronger effect compared to BMI. Peng et al. ${ }^{(19)}$ found that there was a significant increase in the SSI rate when the fat tissue thickness exceeded $4 \mathrm{~cm}$ in patients who underwent spinal surgery (performed multilevel measurements). The route through which surgery was performed was assessed in the study. When comparing the SSI and non-SSI groups, a statistically significant difference 
was found in the DLS measurement results in favour of the SSI group ( $p=0.017)$. After applying additional statistical test, we found that the difference was due to the high DLS values in women $(p=0.008)$. In our study, it was concluded that the length of the surgical path rather than the SFT thickness is an important factor in the occurrence of SSI in women. Our results were similar to those of patients who had undergone a major spinal surgery.

BSA is often used to calculate the doses of treatment agents. Recently, studies have been conducted to link BSA to body weight and obesity ${ }^{(23,24)}$. In obesity, a disproportionate increase in BSA occurs in patients with different weights as the height remains constant. Even though BSA can be calculated using different methods ${ }^{(20,23,24)}$, its results have generally been shown to deviate significantly from the bodyweight curve ${ }^{(20)}$. In our study, BSA has the weakest statistical result $(p=0.569)$ among the four measurements examined. We believe that it is not appropriate to be used in such studies.

\section{CONCLUSION}

To our knowledge, the present study is the first in the literature that investigated the relationship between SSI, SFT and DLS in patients who underwent LDH surgery. Our study revealed that the DLS could be used to predict the risk of SSI occurrence in female patients.

\section{Ethics}

Ethics Committee Approval: This study was approved by the Ethics Committee of University of Health Sciences Turkey, Bağcılar Training and Research Hospital (registration number: 05/15/2020-2020.05.1.05.037).

Informed Consent: Retrospective study.

Peer-review: Internally peer-reviewed.

\section{Authorship Contributions}

Surgical and Medical Practices: I.G., F.K.G., Concept: I.G., F.K.G., Design: I.G., F.K.G., Data Collection or Processing: I.G., Analysis or Interpretation: I.G., F.K.G., Literature Search: I.G., F.K.G., Writing: I.G.

Conflict of Interest: No conflict of interest was declared by the authors.

Financial Disclosure: The authors declared that this study received no financial support.

\section{REFERENCES}

1. Webb ML, Nelson SJ, Save AV, Cui IJ, Lukasiewicz AM, Samuel AM, Cui IJ, Lukasiewicz AM, Samuel AM, et al. Of 20,376 Lumbar Discectomies, 2.6\% of Patients Readmitted Within 30 Days. Spine (Phila Pa 1976). 2017;42:1267-73.

2. Ogihara S, Yamazaki T, Inanami H, Oka H, Maruyama T, Miyoshi K, Oka $\mathrm{H}$, Maruyama T, Miyoshi K, et al. Risk factors for surgical site infection after lumbar laminectomy and/or discectomy for degenerative diseases in adults: A prospective multicenter surveillance study with registry of 4027 cases. PLoS One. 2018;13:1-10.
3. Shousha M, Cirovic D, Boehm H. Infection rate after minimally invasive noninstrumented spinal surgery based on 4350 procedures. Spine (Phila Pa 1976). 2015;40:201-5.

4. Golinvaux NS, Bohl DD, Basques BA, Yacob A, Grauer JN. Comparison of the lumbar disc herniation patients randomized in SPORT to 6,846 discectomy patients from NSQIP: Demographics, perioperative variables, and complications correlate well. Spine J. 2015;15:685-91.

5. Shriver MF, Xie JJ, Tye EY, Rosenbaum BP, Kshettry VR, Benxel EC, et al. Lumbar microdiscectomy complication rates: A systematic review and meta-analysis. Neurosurg Focus. 2015;39:E6.

6. Sherman J, Cauthen J, Schoenberg D, Burns M, Reaven NL, Griffith $\mathrm{SL}$. Economic impact of improving outcomes of lumbar discectomy. Spine J. 2015;10:108-16.

7. Fakouri B, Stovell MG, Allom R. A Comparative Cohort Study of Lumbar Microdiscectomy in Obese and Nonobese Patients. J Spinal Disord Tech. 2015;28:E352-7.

8. Xing $D$, Ma JX, Ma XL, Song $D H$, Wang J, Chen $Y$, et al. A methodological, systematic review of evidence-based independent risk factors for surgical site infections after spinal surgery. Eur Spine J. 2013;22:605-15.

9. Yao R, Zhou H, Choma TJ, Kwon BK, Street J. Surgical Site Infection in Spine Surgery: Who Is at Risk? Glob Spine J. 2018;8:5S-30S.

10. Esfahani DR, Shah H, Arnone GD, Scheer JK, Mehta Al. Lumbar Discectomy Outcomes by Specialty: A Propensity-Matched Analysis of 7464 Patients from the ACS-NSQIP Database. World Neurosurg. 2018; 118:e865-70.

11. Leven D, Passias PG, Errico TJ, Lafage V, Bianco K, Lee A, et al. Risk factors for reoperation in patients treated surgically for intervertebral disc herniation: A subanalysis of eight-year sport data. J Bone Jt Surg Am. 2015;97:1316-25.

12. Pugely AJ, Martin CT, Gao Y, Mendoza-Lattes SA. Outpatient surgery reduces short-term complications in lumbar discectomy: An analysis of 4310 patients from the ACS-NSQIP database. Spine (Phila Pa 1976). 2013;38:264-71

13. Rihn JA, Kurd M, Hilibrand AS, Lurie J, Zhao W, Albert T, et al. The influence of obesity on the outcome of treatment of lumbar disc herniation: Analysis of the Spine Patient Outcomes Research Trial (SPORT). J Bone Jt Surg. 2013;95:1-8.

14. Meredith DS, Huang RC, Nguyen J, Lyman S. Obesity increases the risk of recurrent herniated nucleus pulposus after lumbar microdiscectomy. Spine J. 2010;10:575-80.

15. De Lorenzo A, Deurenberg P, Pietrantuono M, Di Daniele N, Cervelli V, Andreoli A. How fat is obese? Acta Diabetol. 2013; 40:254-257.

16. Mehta Al, Babu R, Karikari IO, Grunch B, Agarwal V], Owens TR, et al. 2012 young investigator award winner: The distribution of body mass as a significant risk factor for lumbar spinal fusion postoperative infections. Spine (Phila Pa 1976). 2012;37:1652-6.

17. Lee JJ, Odeh KI, Holcombe SA, Patel RD, Wang SC, Goulet JA, et al. Fat thickness as a risk factor for infection in lumbar spine surgery. Orthopedics. 2016; 39:e1124-8.

18. Li Z, Liu P, Zhang C, Xu G, Zhang Y, Chang Y, et al. Incidence, prevalence, and analysis of risk factors for surgical site infection after lumbar fusion surgery: $\geq 2$-year follow-up retrospective study. World Neurosurg. 2019;131:e460-e467.

19. Peng W, Liang Y, Lu T, Li M, Li DS, Du KH, et al. Multivariate analysis of incision infection after posterior lumbar surgery in diabetic patients: A single-center retrospective analysis. Med (United States). 2019;98:e15935.

20. Livingston $\mathrm{EH}$, Lee S. Body surface area prediction in normalweight and obese patients. Am J Physiol - Endocrinol Metab. 2001;281:586-91.

21. Smith JS, Shaffrey CI, Sansur CA, Berven SH, Fu KMG, Broadstone PA, et al. Rates of infection after spine surgery based on 108,419 procedures: A report from the Scoliosis Research Society morbidity and mortality committee. Spine (Phila Pa 1976). 2011;36:556-63.

22. Zijlmans JL, Buis DR, Verbaan D, Vandertop WP. Wound drains in non-complex lumbar surgery a systematic review. Bone Jt J. 2016;98B:984-9. 
J Turk Spinal Surg 2020;31(4):245-50

Güleç and Karagöz Güzey. Post-Lumbar Discectomy Wound Infection

turkishspine

23. Sardinha LB, Silva AM, Minderico CS, Teixeira PJ. Effect of body surface area calculations on body fat estimates in non-obese and obese subjects. Physiol Meas. 2006;27:197-209.
24. Verbraecken J, Van De Heyning P, De Backer W, Van Gaal L. Body surface area in normal-weight, overweight, and obese adults. A comparison study. Metabolism. 2006;55:515-24. 